\title{
DESENVOLVIMENTO PUBERAL EM MENINOS COM DOENÇA FALCIFORME NA REGIÃO METROPOLITANA DE FEIRA DE SANTANA Mateus Andrade Alvaia ${ }^{1}$; Carina Oliveira Silva ${ }^{2}$ e Evanilda Souza de Santana Carvalho $^{3}$; José de Bessa Junior ${ }^{4}$ \\ 1. Bolsista PIBIC/CNPq, Graduando em Medicina, Universidade Estadual de Feira de Santana, e-mail: mateus_alvaia@hotmail.com \\ 2. Participante do núcleo UROS saúde de subgrupos, Departamento de Saúde, Universidade Estadual de Feira de Santana, e-mail: carioliveira13@outlook.com \\ 3. Participante do NUDES, Departamento de Saúde, Universidade Estadual de Feira de Santana, e-mail: evasscarvalho@yahoo.com.br \\ 4. Orientador, Departamento de Saúde, Universidade Estadual de Feira de Santana, e-mail: josedebessa@gmail.com
}

PALAVRAS-CHAVE: Doença falciforme; testosterona; meninos.

\section{INTRODUÇÃO}

A doença falciforme (DF) é a hemoglobinopatia mais comum do Brasil e atinge predominante negros e pardos. A distribuição da DF, por região do país é heterogênea e tem maior prevalência no estado da Bahia onde observa-se incidência de 1:650 nascidos vivos (BRASIL, 2015). As complicações desta doença são numerosas e podem afetar todos os sistemas, com significativo impacto na qualidade de vida dessas pessoas, o que faz desta afecção um importante problema de saúde pública no Brasil.

Trata-se de uma doença hereditária em que há substituição do aminoácido ácido glutâmico por valina no códon seis da beta-globina (SUN; XIA, 2013). As principais repercussões são hemólise e eventos vasoclusivos, principalmente nos vasos de pequeno calibre, determinando a origem da maior parte da sintomatologia desta doença (KATO et al., 2009). Os tipos genéticos associados à DF são HbSC e HbSS, sendo esta última relacionado à maior gravidade.

Dentre as inúmeras repercussões, a deficiência de testosterona está associada à DF, mas seu mecanismo subjacente ainda não é conhecido. Acredita-se que pode ser através de uma patologia testicular primária, secundária a infartos testiculares ou a possível infarto hipofisário como uma causa secundária (MUSICKI et al., 2015). Estudos clínicos mostram que existe uma diminuição dos níveis séricos de testosterona em pacientes do sexo masculino com anemia falciforme (ABUDU et al., 2011; OSEGBE; AKINYANJU, 1987).

A secreção de testosterona é regulado pelas células de Leydig nos testículos e tem um papel central no desenvolvimento de características sexuais secundárias e espermatogênese. Sua síntese e secreção estão sob a estimulação do hormônio luteinizante (LH) da adenohipófise. Por isso, a deficiência de testosterona na DF está associada, em crianças e adolescentes, ao retardo do desenvolvimento físico e puberal, perda de massa óssea e, possivelmente, ao priapismo; principalmente em crianças com genótipo HbSS (MUSICKI et al., 2015). Quando adultos, essa deficiência hormonal causa, além de redução da libido, disfunção erétil (MORRISON et al., 2015). A puberdade tardia é definida clinicamente como a ausência dos primeiros sinais de desenvolvimento puberal além do intervalo normal para a população (WILLIAM F CROWLEY, JR, MDNELLY PITTELOUD, 2018). De acordo com os critérios clássicos, meninos pré-púberes na idade de 14 anos ou mais são definidos como tendo atrasado início puberal. Geralmente, esses pacientes tem uma história familiar de 
puberdade atrasada, e provavelmente entrarão na puberdade espontaneamente, embora possam tem um atraso marcado (LAWAETZ et al., 2015).

O retardo na maturação sexual e no desenvolvimento das características sexuais da puberdade pode resultar em baixa auto-estima e outras consequências emocionais, psicológicas e sociais em muitos meninos (OYEDEJI, 1995). E acredita-se que essas repercussões são maximizadas nos jovens com DF que já convivem com inumeras limitações físicas e repercussões clínicas inerentes à doença.

O objetivo específico deste trabalho foi avaliar os desenvolvimento puberal em meninos com doença falciforme acompanhado no Centro de Referência de Tratamento da Doença Falciforme em Feira de Santana.

\section{MATERIAL E MÉTODOS}

Foram avaliados uma amostra de conveniência de pacientes masculinos, com idades entre 4 e 17 anos, com doença falciforme acompanhados pelo Centro de referência em Feira de Santana-Ba. Foram excluídos pacientes sob reposição hormonal, ou acometidos por doença aguda nos 7 dias anteriores à coleta.

$\mathrm{O}$ agendamento foi realizado pela equipe de pesquisa do UROS e a coleta dos dados foi realizado em uma sala reservada para a pesquisa no CSU. No dia da coleta os indivíduos foram devidamente informados de forma verbal e individual a respeito do estudo, com a leitura do Termo de Assentimento Livre e Esclarecido (TALE). Após assinatura do TALE pelos responsáveis das crianças, em conformidade com a Resolução 466/12, os indivíduos foram submetidos à coleta sanguínea e aplicação de questionário estruturado acerca das características sociodemográficas (idade, raça/cor, renda) e referente à doença (tipo de hemoglobinopatia, e presença de episódios de priapismo como complicação da doença).

A análise sorológica da testosterona total foi realizado pelo método EnzymeLinked Immunosorbent Assay (ELISA). Foram considerados normais os valores de TT por idade (nmol / L) entre os percentis 2,5 e 97,5 em concordância ao estudo de (KELSEY et al., 2014).

Para analisar o desenvolvimento sexual fenotípico utilizou-se os critérios de Tanner nos meninos com idade a partir de 10 anos. Essa amostra foi avaliada através de análise visual da presença e distribuição dos pelos pubianos [classificados de P1 (pré adolescência - sem pelugem) até P5 (pelugem do tipo adulto, estendendo-se até a face interna das coxas)] e desenvolvimento genital [classificados de G1 (tipo infantil) até G5 (tipo adulto)]. Os respectivos escores identificados foram assinalados no nomogramas de linhas de estágio de Tanner, implementados no Reino Unido e adequados por (LAWAETZ et al., 2015) em desvios padrão (DP) para permitir uma melhor interpretação dos dados. Valores abaixo de -2 desvios padrão serão considerados como puberdade atrasada. Posteriormente foram relacionados os estágios de Tanner com os dados obtidos da testosterona sérica.

As variáveis quantitativas, contínuas ou ordinais, foram descritas por suas medidas de tendência central (médias ou medianas) e pelas respectivas medidas de dispersão (desvio-padrão, variação interquartil ou valores mínimo e máximo), enquanto as nominais ou qualitativas por seus valores absolutos, percentagens ou proporções. Para comparação das diferenças das variáveis contínuas, foi utilizado o teste $t$ de 
Student ou o teste de Mann-Whitney. Teste de D'Agostino - Pearson será empregado na avaliação do padrão de distribuição das variáveis.

Na comparação dos dados categóricos, foi utilizado os testes de Fisher ou do qui-quadrado e suas variantes.

A associação entre os parâmetros estudados foi expressa pela razão de prevalência ou Odds Ratio. Intervalos de confiança de 95\% foram empregados como medidas de precisão dos resultados. Valores de $\mathrm{p}$ menores que $0,05(\mathrm{p}<0,05)$ foram considerados significativos. Nas análises foi utilizado o programa estatístico computacional GraphPad Prism, versão 7.0.3,GraphPad Software, San Diego-CA, USA.

\section{RESULTADOS E/OU DISCUSSÃO}

No total, foram avaliados 41 meninos com doença falciforme entre 4 e 18 anos de idade e mediana de 8 anos. A renda familiar média de 60,97\% (25/41) dos entrevistados é de um salário mínimo. Em relação ao critério raça/cor, 51,21\% (21/41) de autodeclararam pretas, 36,58\% (15/41) pardos, 7,35 (3/41) brancos, 2,43\% (1/41) amarelo e 2,43\% (1/41) vermelho. Quanto ao tipo de hemoglobinopatia, 63,41\% (26/41) são do tipo HbSS e 36,59\% do tipo HbSC. Episódios de priapismo foi referido em 24,39\% (10/41) dos entrevistados e está relacionado com o tipo HbSS, mais grave. Não houve correlação entre a ocorrência de episódios de priapismo e baixos níveis de TT nesses pacientes, similar ao visto no estudo de (MORRISON et al., 2015).

A TT esteve acima ou dentro dos valores de normalidade em quase todos os casos e só esteve abaixo do percentil 2,5 em apenas um caso, caracterizando um nítido atraso no desenvolvimento sexual laboratorial nesse paciente.

Em relação aos estágios de Tanner, percebe-se que nenhum paciente desta amostra atingiu o estágio 5 (G5 e P5). Quatro pacientes, particularmente os de maior idade (entre 14 e 18 anos), estiveram no limite inferior ou abaixo de -2 desvios padrões, em relação ao desenvolvimento genital e de pelos pubianos, o que demonstra atraso no desenvolvimento sexual nessas crianças. A relação entre os estágios de Tanner e a TT também sugere um aparente atraso no desenvolvimento dos caracteres sexuais secundários, ou seja, a puberdade nessa população tem um início mais tardio.

Deve-se pontuar que níveis séricos de TT sofre influência do status socioeconômico, estado nutricional, localização geográfica, desnutrição e clima quente, o que pode ter influenciado os resultados obtidos nesta pesquisa.

\section{CONSIDERAÇÕES FINAIS}

Embora a literatura mostre que exista uma relação entre DF e baixos níveis de TT em pacientes infantis masculinos (HUANG; MUNEYYIRCI-DELALE, 2017; MORRISON et al., 2015), este trabalho, não encontrou resultados semelhantes. Percebeu-se, que que existe um atraso do desenvolvimento puberal nessa população. Retardo no amadurecimento sexual pode causar repercussões sistêmicas e psicológicas na vida dessas crianças. Mais estudos são necessários para esclarecer e quantificar o atraso no desenvolvimento puberal, com maiores amostras populacionais, a fim de possibilitar maior entendimento desta temática e por fim poder instituir terapias eficientes e de forma mais precoce. 


\section{REFERÊNCIAS}

1. ABUDU, E. K. et al. Serum testosterone levels of HbSS (sickle cell disease) male subjects in Lagos, Nigeria. BMC research notes, v. 4, p. 298, 17 ago. 2011.

2. HUANG, A. W.; MUNEYYIRCI-DELALE, O. Reproductive endocrine issues in men with sickle cell anemia. Andrology, v. 5, n. 4, p. 679-690, jul. 2017.

3. KATO, G. J. et al. Vasculopathy in sickle cell disease: Biology, pathophysiology, genetics, translational medicine, and new research directions. American journal of hematology, v. 84, n. 9, p. 618-25, set. 2009.

4. KELSEY, T. W. et al. A validated age-related normative model for male total testosterone shows increasing variance but no decline after age 40 years. PloS one, v. 9, n. 10, p. e109346, 2014.

5. LAWAETZ, J. G. et al. Evaluation of 451 Danish Boys With Delayed Puberty: Diagnostic Use of a New Puberty Nomogram and Effects of Oral Testosterone Therapy. The Journal of Clinical Endocrinology \& Metabolism, v. 100, n. 4, p. 1376-1385, abr. 2015.

6. MORRISON, B. F. et al. Is testosterone deficiency a possible risk factor for priapism associated with sickle-cell disease? International urology and nephrology, v. 47, n. 1, p. 47-52, jan. 2015.

7. MUSICKI, B. et al. Mechanism of testosterone deficiency in the transgenic sickle cell mouse. PloS one, v. 10, n. 5, p. e0128694, 2015.

8. OSEGBE, D. N.; AKINYANJU, O. O. Testicular dysfunction in men with sickle cell disease. Postgraduate medical journal, v. 63, n. 736, p. 95-8, fev. 1987.

9. OYEDEJI, G. A. Delayed sexual maturation in sickle cell anaemia patientsobservations in one practice. Annals of Tropical Paediatrics, v. 15, n. 3, p. 197201, 13 set. 1995.

10. SUN, K.; XIA, Y. New insights into sickle cell disease. Current Opinion in Hematology, v. 20, n. 3, p. 215-221, maio 2013.

11. WILLIAM F CROWLEY, JR, MDNELLY PITTELOUD, M. Approach to the patient with delayed puberty - UpToDate. Disponível em:

$<$ https://www.uptodate.com/contents/approach-to-the-patient-with-delayedpuberty $>$. Acesso em: 6 ago. 2018. 